\title{
Periodic Variation and Its Effect on Management and Prognosis of Korean Patients With Acute Myocardial Infarction
}

\author{
Hyo Eun Park, $\mathrm{MD}^{1}$; Bon-Kwon Koo, MD, $\mathrm{PhD}^{1}$; Wonjae Lee, $\mathrm{MD}^{1}$; Youngjin Cho, $\mathrm{MD}^{1}$; \\ Jin Sik Park, MD, $\mathrm{PhD}^{2}$; Ji-Yong Choi, $\mathrm{MD}, \mathrm{PhD}^{3}$; Myung-Ho Jeong, $\mathrm{MD}, \mathrm{PhD}^{4}$; \\ Jong Hyun Kim, MD ${ }^{5}$; Shung Chull Chae, MD, $\mathrm{PhD}^{6}$; Young Jo Kim, MD, $\mathrm{PhD}^{7}$; \\ Chang-Wook Nam, MD, $\mathrm{PhD}^{8}$; Jae-Hwan Lee, $\mathrm{MD}, \mathrm{PhD}^{9}$; Dong Hoon Choi, $\mathrm{MD}, \mathrm{PhD}^{10}$; \\ Taek Jong Hong, $\mathrm{MD}, \mathrm{PhD}^{11}$; Jei Keon Chae, $\mathrm{MD}, \mathrm{PhD}^{12}$; Jae Young Rhew, $\mathrm{MD}^{13}$; \\ Kee Sik Kim, MD, $\mathrm{PhD}^{3}$; Hyo-Soo Kim, MD, $\mathrm{PhD}^{1}$; Byung-Hee Oh, MD, $\mathrm{PhD}^{1}$; \\ Young Bae Park, $\mathrm{MD}, \mathrm{PhD}^{1}$ for KAMIR investigators
}

\begin{abstract}
Background: The characteristics of the periodic variation in acute myocardial infarction (AMI) and the subsequent effect on management and prognosis have not been fully investigated in a large number of Asian populations.
\end{abstract}

\begin{abstract}
Methods and Results: From a prospective, observational multicenter online registry, 4,573 patients diagnosed as AMI in Korea from January to December 2006 were included. The highest incidence of AMI was between 8 a.m. and noon. The number of cases was highest in the winter and lowest in the autumn (13.6 vs 11.4 patients per day, $\mathrm{P}<0.001)$. Patients with symptom onset during working hours had a shorter time to first medical contact $(203 \pm 288 \mathrm{~min})$ compared with out-of-hours onset $(230 \pm 288 \mathrm{~min}, \mathrm{P}=0.003)$. In patients who underwent primary angioplasty, out-of hours symptom onset was associated with a greater time delay in both the patient's and the medical facility's response (door-to-balloon time out-of hours vs working hours: $101 \pm 54$ min vs $84 \pm 44 \mathrm{~min}, \mathrm{P}<0.001$ ). In patients with ST-segment elevation myocardial infarction, symptoms to first medical contact showed a significant relationship to in-hospital mortality (for every $10 \mathrm{~min}$ of symptoms to first medical contact, odds ratio 1.006 , $95 \%$ confidence interval 1.001-1.012, $\mathrm{P}=0.018$ )
\end{abstract}

Conclusions: Circadian and periodic variation in AMI exists in Korean patients, which resulted in different patient behavior, hospital management and outcomes. (Circ J 2010; 74: 970-976)

Key Words: Acute myocardial infarction; Circadian variation; Periodic variation

A fter Pell and d'Alonzo first identified the association of circadian variation and acute myocardial infarction (AMI), ${ }^{1}$ many studies have shown similar patterns, with the peak onset in the morning, ${ }^{2}$ on Monday and in the winter. ${ }^{3-5}$ The physiological changes in hemodynamics, ${ }^{6-8}$ vascular status and hematological changes, ${ }^{9-12}$ as well as environmental factors, contribute to this variation. ${ }^{2-4,13}$ These circadian variations are also associated with the patient's response, medical management and prognosis. ${ }^{14}$

Some reports have suggested that there may be ethnic differences in circadian variation and its association with AMI. Lopez et al reported a difference in the onset of AMI among British Caucasians, Indo-Asians and Mediterranean Caucasians. ${ }^{15}$ However, there has not been a large-scale study in

Received May 17, 2009; accepted January 13, 2010; released online March 30, 2010 Time for primary review: 23 days

${ }^{1}$ Division of Cardiology, Department of Internal Medicine, College of Medicine, Seoul National University, Seoul, ${ }^{2}$ Department of Internal Medicine, Sejong General Hospital, Bucheon, ${ }^{3}$ Division of Cardiology, Department of Internal Medicine, College of Medicine, Daegu Catholic University, Daegu, ${ }^{4}$ Division of Cardiology, Department of Internal Medicine, College of Medicine, Chonnam National University, Gwangju, ${ }^{5}$ Busan Hanseo Hospital, Busan, ${ }^{6}$ Division of Cardiology, Kyungpook National University Hospital, ${ }^{7}$ Division of Cardiology, Yeungnam University Medical Center, ${ }^{8}$ Division of Cardiology, Keimyung University Dongsan Medical Center, Daegu, ${ }^{9}$ Division of Cardiology, Chungnam National University Hospital, Daejeon, ${ }^{10}$ Division of Cardiology, Yonsei University Severans Hospital, Seoul, ${ }^{11}$ Division of Cardiology, Pusan National University Hospital, Busan, ${ }^{12}$ Division of Cardiology, Chonbuk National University Hospital and ${ }^{13}$ Jeonju Presbyterian Medical Center, Jeonju, Korea

Mailing address: Bon-Kwon Koo, MD, PhD, Department of Internal Medicine, Seoul National University Hospital, 101 Daehang-ro, Chongno-gu, Seoul 110-744, Korea. E-mail: bkkoo@snu.ac.kr and Kee Sik Kim, MD, PhD, Heart Center Daegu Catholic University, Medical Center 3056-6, Daemyung 4 Dong, Nam-gu, Daegu 705-718, Korea. E-mail: kks7379@cu.ac.kr

ISSN-1346-9843 doi:10.1253/circj.CJ-09-0344

All rights are reserved to the Japanese Circulation Society. For permissions, please e-mail: cj@j-circ.or.jp 


\begin{tabular}{|lcccc|}
\hline \multicolumn{2}{|l}{ Table 1. Baseline Characteristics of the Patients } & & & \\
& All & Working hours & Out-of-hours & P value* $^{*}$ \\
Total no. of patients & 4,573 & 1,265 & 3,308 & \\
Age (years) & $62.9 \pm 12.7$ & $63.1 \pm 12.7$ & $62.8 \pm 12.7$ & 0.443 \\
Male & $3,281(71.7 \%)$ & $893(70.6 \%)$ & $2,388(72.2 \%)$ & 0.284 \\
Previous IHD & $778(17.0 \%)$ & $213(16.8 \%)$ & $565(17.1 \%)$ & 0.846 \\
Anterior MI & $2,049(44.8 \%)$ & $542(42.8 \%)$ & $1,507(45.6 \%)$ & 0.076 \\
STEMI & $2,912(63.7 \%)$ & $836(66.1 \%)$ & $2,076(62.8 \%)$ & 0.036 \\
Primary PCI & $1,410(48.4 \%)$ & $472(56.5 \%)$ & $938(45.2 \%)$ & $<0.001$ \\
Thrombolysis & $400(13.7 \%)$ & $70(8.4 \%)$ & $330(15.9 \%)$ & $<0.001$ \\
Risk factors & & & & \\
Diabetes mellitus & $1,246(27.2 \%)$ & $330(26.1 \%)$ & $916(27.7 \%)$ & 0.276 \\
Hyperlipidemia & $325(7.1 \%)$ & $98(7.7 \%)$ & $227(6.9 \%)$ & 0.298 \\
HTN & $2,186(47.8 \%)$ & $595(47.0 \%)$ & $1,591(48.1 \%)$ & 0.521 \\
Time to first medical contact (min) & $223 \pm 288$ & $203 \pm 288$ & $230 \pm 288$ & 0.003 \\
CK-MB (maximum, $\mathrm{ng} / \mathrm{ml})$ & $155.2 \pm 232.6$ & $156.3 \pm 242.0$ & $154.7 \pm 229.0$ & 0.837 \\
Cardiogenic shock & $229(5.0 \%)$ & $61(4.8 \%)$ & $168(5.1 \%)$ & 0.722 \\
\hline
\end{tabular}

*Working hour vs out-of-hours onset of symptom.

IHD, ischemic heart disease; MI, myocardial infarction; STEMI, ST-segment elevation Ml; PCI, percutaneous coronary intervention; HTN, hypertension.
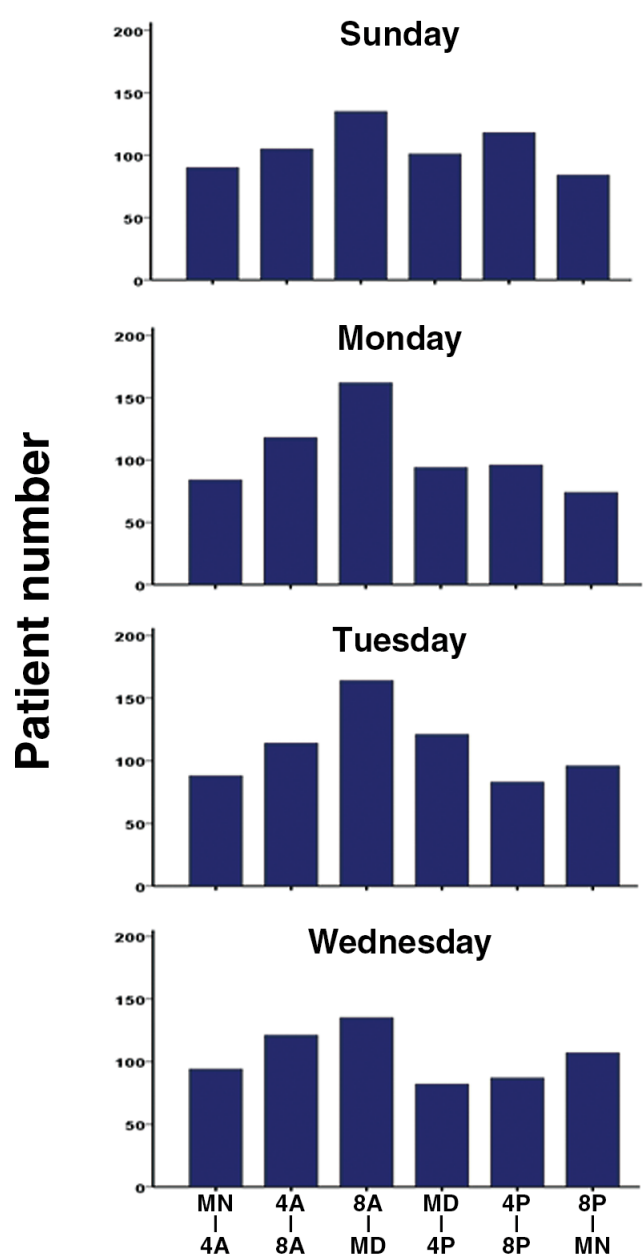

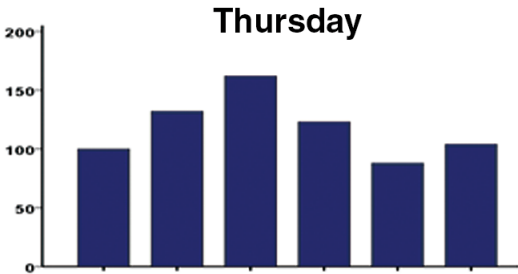

Friday
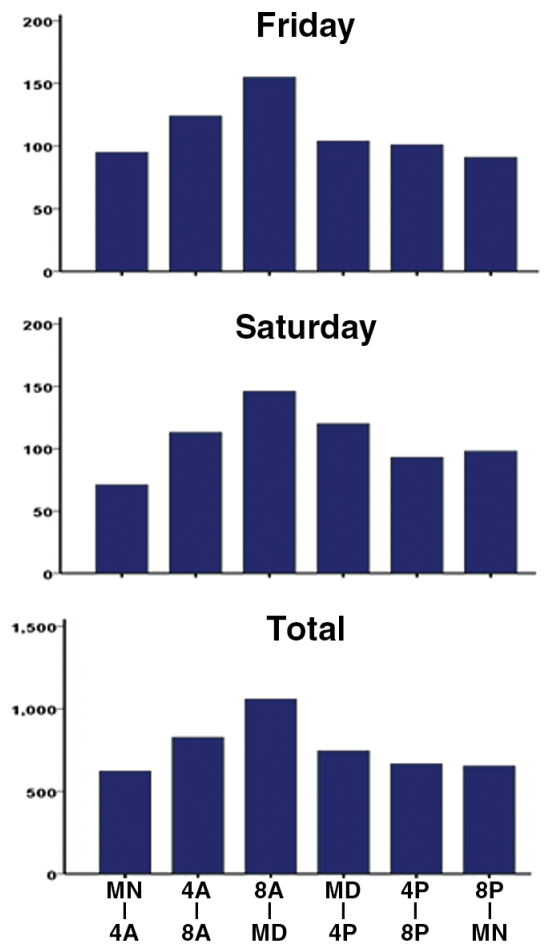

Time of day (h)

Figure 1. Histograms of circadian variation in the incidence of acute myocardial infarction by 6 4-h periods according to weekday. MD, midday; MN, midnight; A, AM; P, PM. 


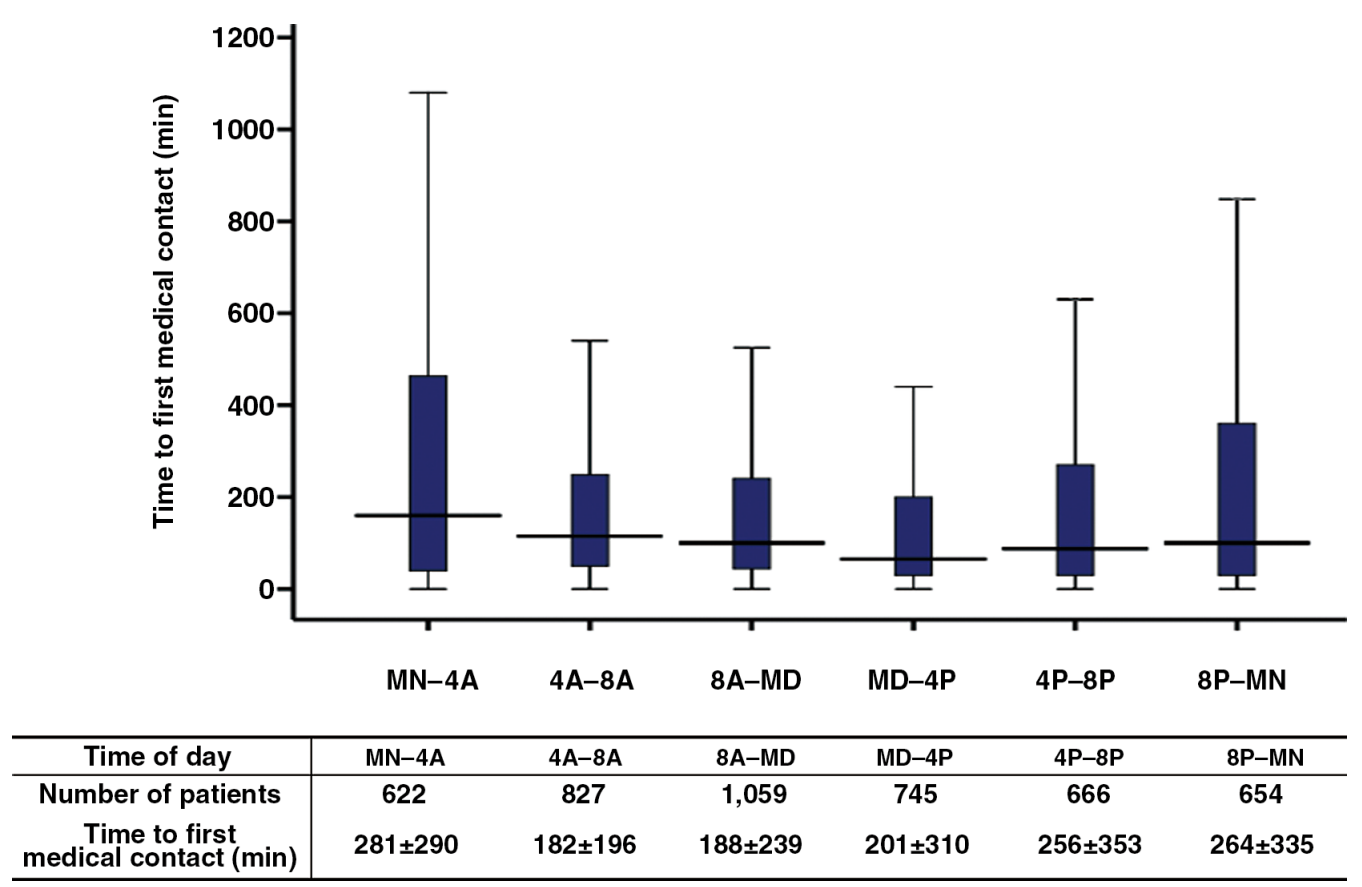

Figure 2. Box plots of time to first medical contact according to the time of symptom onset in all patients with acute myocardial infarction. The time of onset of symptom was divided into 6 equal parts of $4 \mathrm{~h}$ each and each box plot shows minimum, first quartile, median, third quartile, and maximum value in minutes during each time period. The table represents time to first medical contact in mean \pm standard deviations. MD, midday; MN, midnight; A, AM; P, PM.

Asians with regard to the circadian variation of AMI and the effect on medical management and prognosis.

\section{Methods}

The Korea Acute Myocardial Infarction Registry (KAMIR) is a prospective, observational multicenter online registry that has been investigating the risk factors associated with mortality in patients with AMI since November 2005. The registry receives data from 41 primary percutaneous coronary intervention (PCI) centers in Korea. ${ }^{16,17}$ Between January and December of 2006, 5,421 patients were included and after exclusion of 848 patients who were younger than 20 years, who had visited the hospital more than $24 \mathrm{~h}$ after the onset of symptoms, or whose time of symptom onset or time of arrival to the first hospital was unclear, 4,573 patients were finally included in this study.

The diagnosis of AMI was based on the clinical presentation, ECG findings and levels of cardiac enzymes. ${ }^{18}$ Patients who presented with acute ST-segment elevation MI (STEMI) within $12 \mathrm{~h}$ of symptom onset were considered eligible for primary angioplasty. The time to first medical contact was defined as the time interval between the first recognition of pain to the first visit to a medical facility. In the case of referral to a study hospital, the time interval from symptom onset to the visit to the first hospital was used as the time to the first medical contact. In patients who underwent primary PCI, treatment delay was defined as the time taken from symptom onset to first ballooning, which is the sum of the time to first medical contact, transfer to a PCI center and the door to balloon time. Working hours were defined as Monday to Friday between 8 a.m. and 6 p.m. Weekends were considered as out-of-hours. The patients were classified into working hours or out-of-hours onset according to the time of symptom onset. The frequency of AMI was defined as the number of patients per day. The in-hospital mortality included allcause mortality during hospitalization.

Data are presented as the mean \pm standard deviation for continuous variables and as frequencies for categorical variables. Comparisons of the continuous variables were performed using Student's t-test or ANOVA. Analyses of discrete variables were performed using the chi-square test. The weekly, monthly and seasonal variations were evaluated by comparing the mean number of AMI events per day using ANOVA. Regression analyses were performed to determine the factors associated with the time to medical contact and in-hospital mortality. A value of $\mathrm{P}<0.05$ was considered significant. All statistical analyses were carried out with SPSS version 17.0 (Chicago, IL, USA).

\section{Results}

Baseline characteristics of the patients are shown in Table $\mathbf{1 .}$ Depending on the time of symptom onset, patients showed different patterns of presentation. Among 4,573 patients, 1,265 presented with symptom during working hours and 3,308 patients during out-of-hours. Compared with patients with out-of-hours onset, patients with onset during working hour presented more frequently with STEMI, presented to the hospital earlier and underwent primary PCI more frequently. More patients received thrombolysis out-of-hours.

\section{Periodic Variation in the Onset of AMI}

To examine the periodic variation in AMI, we analyzed its 


\begin{tabular}{|lcccc|}
\hline \multicolumn{2}{l}{ Table 2. Determinants of the Time to First Medical Contact in Patients With Myocardial Infarction } & \\
& $\beta$ & 95\% confidence interval & P value \\
\cline { 3 - 4 } & & Lower bound & Upper bound & \\
Age (years) & 2.017 & 1.36 & 2.68 & $<0.001$ \\
Female & 15.26 & -4.56 & 35.09 & 0.13 \\
Diabetes mellitus & 25.71 & 6.85 & 44.57 & 0.008 \\
Non-STEMI & 73.38 & 55.97 & 90.79 & $<0.001$ \\
IHD & -20.67 & -42.92 & 1.59 & 0.069 \\
HTN & 15.73 & -1.32 & 32.77 & 0.07 \\
Out-of-hours symptom onset (min) & 25.55 & 7.16 & 43.94 & 0.006 \\
Cardiogenic shock & -22.48 & -60.43 & 15.47 & 0.25 \\
\hline
\end{tabular}

Abbreviations see in Table 1.

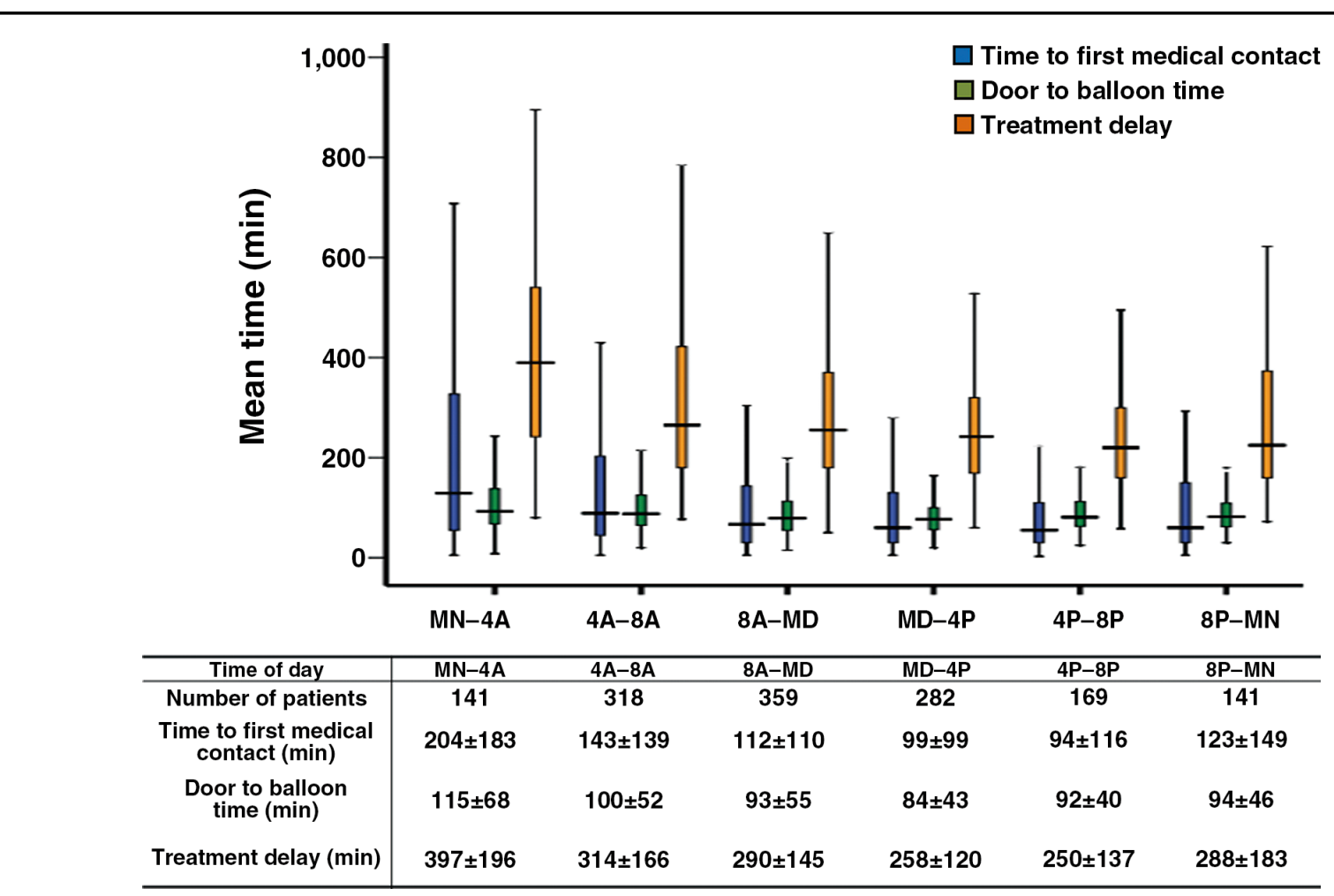

Figure 3. Box plots of time to first medical contact $(\square)$, door to balloon time $(\square)$ and treatment delay ( $\square$ ) according to the 6 4-h periods in patients with acute ST-segment elevation myocardial infarction who underwent primary angioplasty. Treatment delay is the sum of time to first medical contact, transfer time to the $\mathrm{PCl}$ center and door to balloon time. Each box plot shows minimum, first quartile, median, third quartile, and maximum value during each time period, and the values in the table are mean \pm standard deviations. MD, midday; MN, midnight; $A, A M ; P, P M$.

incidence according to the time of the day, weekday, each season and month. The 24-h day was divided into 6 equal parts of $4 \mathrm{~h}$ each to evaluate the diurnal variation. AMI developed most frequently between 8 a.m. and noon. When analyzed according to weekday, all weekdays had the same tendency of a primary peak between $8 \mathrm{a} . \mathrm{m}$. and noon, but the secondary peak showed variability depending on the weekday (Figure 1).

The total frequency for AMI did not differ among the weekdays, but there were significant seasonal and monthly variations. The 12 months were divided into 4 seasons, with each season consisting of 3 consecutive months. The seasonal variation showed a peak incidence of 13.6 patients per day in winter, and decreased to the lowest frequency of 11.4 patients per day in the fall $(\mathrm{P}<0.001)$. The monthly variation showed the highest incidence in January with 16.0 patients per day and lowest in November with 10.6 patients per day $(\mathrm{P}<0.001)$.

\section{Effect of the Time of Symptom Onset on Patient Behavior and Subsequent Medical Management}

The mean time to first medical contact was $223 \pm 288 \mathrm{~min}$. The time to the first medical contact was affected by the time of symptom onset (Figure 2). Patients with symptom onset during working hours had a shorter time to their first medical contact $(203 \pm 288 \mathrm{~min})$ than those with out-of hours symptom 
onset $(230 \pm 288 \mathrm{~min}, \mathrm{P}=0.003)$. The multivariate analysis showed that the time to first medical contact was delayed in patients with advanced age, who had diabetes mellitus, non-STEMI (NSTEMI), and onset of symptoms out-of-hours (Table 2).

The door-to-balloon time in patients with a STEMI who underwent a primary PCI differed according to the time of symptom onset (Figure 3). It was longer for presentation outof-hours than for presentation during working hours (101士 54 min vs $84 \pm 44 \mathrm{~min}, \mathrm{P}<0.001)$. The time to first medical contact and treatment delay were also longer out-of-hours (out-of-hours vs working hours: $135 \pm 144 \mathrm{~min}$ vs $104 \pm 104 \mathrm{~min}$, $\mathrm{P}<0.001$ for time to first medical contact, $309 \pm 170 \mathrm{~min}$ vs $266 \pm 132$ min, $\mathrm{P}<0.001$ for treatment delay). However, when only the patients who presented to the hospital within $3 \mathrm{~h}$ of symptom onset were analyzed, the mean time to first medical contact and the treatment delay did not differ between out-ofhours and working hours onset $(65 \pm 45 \mathrm{~min}$ vs $64 \pm 46 \mathrm{~min}$, $\mathrm{P}=0.788,241 \pm 111 \mathrm{~min}$ vs $231 \pm 105 \mathrm{~min}, \mathrm{P}=0.122$, respectively). The weekday, month and season were not associated with the door-to-balloon time.

\section{Effect of the Time of Symptom Onset on Prognosis}

During hospitalization, 50 patients $(4.0 \%)$ among those with working hours onset and 159 patients $(4.8 \%)$ with out-ofhours onset died. A multivariate analysis was performed to determine the factors associated with in-hospital mortality, including the variables of age, sex, previous history of ischemic heart disease, hypertension or diabetes mellitus, final diagnosis of STEMI, time to first medical contact, and cardiogenic shock at initial presentation. The determinants of in-hospital mortality were advanced age (odds ratio (OR) $1.052,95 \%$ confidence interval (CI) 1.037-1.067), diabetes mellitus (OR 1.472, 95\% CI 1.079-2.009), STEMI (OR 1.632, 95\%CI 1.171-2.274), and cardiogenic shock (OR 11.688, 95\%CI 8.305-16.450) among all patients, and advanced age (OR 1.056, 95\%CI 1.028-1.086), diabetes mellitus (OR 2.080 , 95\% CI 1.134-3.813) and cardiogenic shock (OR 11.055 , 95\%CI 5.800-21.071) among patients who were eligible for primary PCI. In either case, the time to first medical contact, the time of symptom onset to the first ballooning or symptom onset during working hours/out-of-hours did not affect in-hospital mortality.

We then evaluated patients according to the final diagnosis. In patients who presented as NSTEMI, time to the first medical contact did not show a significant relationship to the in-hospital mortality $(\mathrm{P}=0.165)$. However, in patients with STEMI, time to first medical contact showed a significant relationship with in-hospital mortality (for every $10 \mathrm{~min}$ of symptom to first medical contact, OR 1.006 , 95\%CI 1.001$1.012, \mathrm{P}=0.018$ ). When patients with reperfusion therapy were compared with those without reperfusion therapy, there was no significant relationship between time to first medical contact and in-hospital mortality in either group $(\mathrm{P}=0.413$ in reperfusion group, $\mathrm{P}=0.529$ in no reperfusion group).

\section{Discussion}

This is the largest study analyzing periodic variation and AMI in Asian patients. ${ }^{13,19-22}$ In general, our study showed similar patterns of periodic variation as in Western populations. However, the weekly and seasonal patterns showed some differences. We have also found that the time of symptom onset affected patient behavior and hospital management.

In this study, the periodic variation in the frequency of AMI in Korean patients showed similar diurnal, monthly and seasonal patterns to patients in Western cultures: peak incidence in the early morning, ${ }^{2,3}$ during January and in winter. ${ }^{3-5,23}$ However, the frequency of AMI in Korean patients was lowest in the autumn, whereas in most of the previous studies it has been reported to be lowest during the summer. ${ }^{3-5,23}$ The difference in regional climate may have contributed to the different seasonal patterns observed in Korean AMI patients, because the occurrence of AMI is affected by climate, with a higher incidence in climates with extreme temperatures. . $^{34-27}$ A similar finding with an autumn nadir was also reported in a Japanese study. ${ }^{22}$

In this study, we found no weekday variation of AMI in Korean patients, which was different from other previous reports. Kinjo et al reported a gender difference in the weekday variation in the Japanese population, with women showing a Saturday peak. ${ }^{28}$ Our Korean patient population did not show such sex differences in weekday variation. The monthly and seasonal variations also did not show a sex difference.

The diurnal variation of AMI showed a variable second peak based on the weekday. Kinjo et al suggested socioeconomic factors related to work and lifestyle as an explanation for the secondary peak, especially in young male workers. ${ }^{19}$ Because our data did not include such information, we could not analyze the effect of socioeconomic factors.

In addition to diurnal and seasonal variations we compared patients with working hours vs out-of-hours onset to find differences in patient behavior, management and prognosis. Previous reports by Magid et $\mathrm{al}^{14}$ and Nakayama et $\mathrm{al}^{29}$ observed a longer door to balloon time out-of-hours than during regular hours, which we have also noted. We found differences in patient behavior and hospital management according to the time of symptom onset. When symptom onset occurred during working hours, there was earlier hospital presentation and a shorter door-to-balloon time, whereas out-of-hours both hospital presentation and door to balloon time were significantly longer. The treatment delay out-ofhours may be caused by delayed visiting by the patients after symptom onset and also a delay in the time taken to activate the catheterization laboratory. The time to first medical contact can be shortened by educating patients and the general population, and the door to balloon time can be shortened by improving the activation system of the catheterization laboratory out-of-hours. Also, improving the referral system between hospitals will shorten the total treatment delay. Other factors that affected the time to the first medical contact were advanced age, diabetes mellitus and the diagnosis of NSTEMI. Delayed hospital visit by elderly patients may have been due to atypical symptoms or reduced perception of pain. ${ }^{30,31}$ Autonomic dysfunction and decreased perception of pain in diabetic patients may contribute to a higher incidence of silent MI and subsequent delay in presentation to the hospital. ${ }^{32-34}$ Therefore, a more cautious approach is required when evaluating the elderly or diabetic MI patient.

Higher in-hospital mortality occurred in patients of advanced age, with diabetes mellitus, initial cardiogenic shock, and a diagnosis of STEMI in our study. However, presentation out-of hours was not associated with higher in-hospital mortality despite the longer symptom to first medical contact and door-to-balloon time. It is well known that time-to-reperfusion is an important determinant of the short- and long-term outcomes in patients with AMI. ${ }^{35-38}$ Previous reports have shown that shorter time-to-reperfusion is an independent predictor of in-hospital mortality, especially with a cut-off value of $3 h{ }^{35}$ To understand the discrepancy between previ- 
ous reports ${ }^{14,39}$ and our findings, we divided patients according to the time to first medical contact and compared the time variation. Among the patients who were eligible for primary angioplasty, $77 \%$ of patients visited hospital within $3 \mathrm{~h}$ of symptom onset and there was no difference in either symptom to first medical contact time or treatment delay according to the time of symptom onset in this group.

Another possible explanation of our result is the different study population. Magid et al evaluated 68,439 patients with STEMI and reported increased in-hospital mortality and longer time to treatment for PCI with symptom onset occurring out-of-hours, ${ }^{14}$ whereas Jneid et al found no measurable differences in the in-hospital mortality of 62,814 patients with AMI according to time of symptom onset, despite slightly fewer primary PCI and overall revascularizations and significantly longer door-to-balloon times for those with out-of hours onset. ${ }^{40}$ The difference in study cohorts may have lead to different results: in the study by Magid et al ${ }^{14}$ only the patients with STEMI were included, whereas Jneid et $\mathrm{al}^{40}$ included both STEMI and NSTEMI. We had similar findings to those earlier reports. When all AMI patients were included in the analysis, we could not find a significant relationship between symptom to first medical contact and in-hospital mortality, but when patients with STEMI were analyzed separately, there was significant relationship between symptom to first medical contact and in-hospital mortality.

When patients were grouped according to the presence or absence of reperfusion therapy, we could not find a significant relationship between time to the first medical contact and in-hospital mortality in either group $(\mathrm{P}=0.413$ in reperfusion group, $\mathrm{P}=0.529$ in no reperfusion group). There may have been a survivor-cohort effect, wherein those who present to the hospital after 6-12h have already survived the high-risk period of death. Also, we do not have information on patients in the catchment areas who had an out-of-hospital MI and died prior to hospital arrival, which may have also affected the result.

\section{Study Limitations}

First, there is the possibility of selection bias, as this study includes patients who visited 41 collaborating hospitals in Korea. Second, detailed data on infarct size, socioeconomic status and procedural outcomes were not included in the analysis. These data might have added additional insight to the findings. Third, the results of the current study are based on the analysis of patients during only 1 year, and for better understanding, long-term follow up may be needed. Fourth, the severity of symptoms in each patient was not recorded on an objective scale, such as the VAS scale. The behavior of patients may have been affected by the severity of the symptoms, but could not be evaluated because of the lack of objective or comparable data.

\section{Acknowledgments}

This study was supported by a grant from the Innovative Research Institute for Cell Therapy, Seoul National University Hospital (A062260), and the Clinical Research Center for Ischemic Heart Disease, Seoul, Republic of Korea (0412-CR02-0704-0001) sponsored by the Ministry of Health \& Welfare, Republic of Korea.

\section{Disclosures}

None.

\section{References}

1. Pell S, D'Alonzo CA. Acute myocardial infarction in a large indus- trial population: Report of a 6-year study of 1,356 cases. JAMA 1963; 185: 831-838.

2. Bhalla A, Sachdev A, Lehl SS, Singh R, D'Cruz S. Ageing and circadian variation in cardiovascular events. Singapore Med J 2006; 47: $305-308$

3. Marchant B, Ranjadayalan K, Stevenson R, Wilkinson P, Timmis AD. Circadian and seasonal factors in the pathogenesis of acute myocardial infarction: The influence of environmental temperature. Br Heart J 1993; 69: 385-387.

4. Manfredini R, Boari B, Smolensky MH, Salmi R, Gallerani M, Guerzoni F, et al. Seasonal variation in onset of myocardial infarction: A 7-year single-center study in Italy. Chronobiol Int 2005; 22: $1121-1135$

5. Ornato JP, Peberdy MA, Chandra NC, Bush DE. Seasonal pattern of acute myocardial infarction in the National Registry of Myocardial Infarction. J Am Coll Cardiol 1996; 28: 1684-1688.

6. Feng DL, Tofler GH. Diurnal physiologic processes and circadian variation of acute myocardial infarction. J Cardiovasc Risk 1995; 2: 494-498.

7. Soylu A, Yazici M, Duzenli MA, Tokac M, Ozdemir K, Gok H. Relation between abnormalities in circadian blood pressure rhythm and target organ damage in normotensives. Circ J 2009; 73: 899904.

8. Kim KI, Lee JH, Chang HJ, Cho YS, Youn TJ, Chung WY, et al. Association between blood pressure variability and inflammatory marker in hypertensive patients. Circ J 2008; 72: 293-298.

9. Gottlieb SO. Circadian patterns of myocardial ischemia: Pathophysiologic and therapeutic considerations. J Cardiovasc Pharmacol 1988; 12(Suppl 7): S18-S21.

10. Bull GM, Brozovic M, Chakrabarti R, Meade TW, Morton J, North WR, et al. Relationship of air temperature to various chemical, haematological, and haemostatic variables. J Clin Pathol 1979; 32: $16-20$.

11. Woodhouse PR, Khaw KT, Plummer M, Foley A, Meade TW. Seasonal variations of plasma fibrinogen and factor VII activity in the elderly: Winter infections and death from cardiovascular disease. Lancet 1994; 343: 435-439.

12. Stout RW, Crawford V. Seasonal variations in fibrinogen concentrations among elderly people. Lancet 1991; 338: 9-13.

13. Chiang HT, Lin SL, Ku CS, Liu CP. Circadian and weekly variations in pain onset of acute myocardial infarction. Zhonghua Yi Xue Za Zhi (Taipei) 1999; 62: 334-340.

14. Magid DJ, Wang Y, Herrin J, McNamara RL, Bradley EH, Curtis $\mathrm{JP}$, et al. Relationship between time of day, day of week, timeliness of reperfusion, and in-hospital mortality for patients with acute STsegment elevation myocardial infarction. JAMA 2005; 294: 803812 .

15. Lopez F, Lee KW, Marin F, Roldan V, Sogorb F, Caturla J, et al. Are there ethnic differences in the circadian variation in onset of acute myocardial infarction? A comparison of 3 ethnic groups in Birmingham, UK and Alicante, Spain. Int J Cardiol 2005; 100: $151-154$.

16. Lee KH, Jeong MH, Ahn YK, Kim JH, Chae SC, Kim YJ, et al. Gender differences of success rate of percutaneous coronary intervention and short term cardiac events in Korea Acute Myocardial Infarction Registry. Int J Cardiol 2008; 130: 227-234.

17. Lee SR, Jeong MH, Ahn YK, Chae SC, Hur SH, Kim YJ, et al. Clinical safety of drug-eluting stents in the Korea acute myocardial infarction registry. Circ J 2008; 72: 392-398.

18. Thygesen K, Alpert JS, White HD, Jaffe AS, Apple FS, Galvani $\mathrm{M}$, et al. Universal definition of myocardial infarction. Circulation 2007; 116: 2634-2653.

19. Kinjo K, Sato H, Shiotani I, Kurotobi T, Ohnishi Y, Hishida E, et al. Circadian variation of the onset of acute myocardial infarction in the Osaka area, 1998-1999: Characterization of morning and nighttime peaks. Jpn Circ J 2001; 65: 617-620.

20. Tanaka A, Kawarabayashi T, Fukuda D, Nishibori Y, Sakamoto T, Nishida Y, et al. Circadian variation of plaque rupture in acute myocardial infarction. Am J Cardiol 2004; 93: 1-5.

21. Kinoshita N, Imai K, Kinjo K, Naka M. Longitudinal study of acute myocardial infarction in the southeast Osaka district from 1988 to 2002. Circ J 2005; 69: 1170-1175.

22. Yamasaki F, Seo H, Furuno T, Hamashige N, Kawai K, Owaki T, et al. Effect of age on chronological variation of acute myocardial infarction onset: Study in Japan. Clin Exp Hypertens 2002; 24: 1 9.

23. Spencer FA, Goldberg RJ, Becker RC, Gore JM. Seasonal distribution of acute myocardial infarction in the second National Registry of Myocardial Infarction. J Am Coll Cardiol 1998; 31: 1226-1233.

24. Mannino JA, Washburn RA. Environmental temperature and mor- 
tality from acute myocardial infarction. Int J Biometeorol 1989; 33: $32-35$.

25. Thakur CP, Anand MP, Shahi MP. Cold weather and myocardial infarction. Int J Cardiol 1987; 16: 19-25.

26. Gonzalez Hernandez E, Cabades O'Callaghan A, Cebrian Domenech J, Lopez Merino V, Sanjuan Manez R, Echanove Errazti I, et al. Seasonal variations in admissions for acute myocardial infarction: The PRIMVAC study. Rev Esp Cardiol 2004; 57: 12-19 (in Spanish).

27. Heyer HE, Teng HC, Barris W. The increased frequency of acute myocardial infarction during summer months in a warm climate; a study of 1,386 cases from Dallas, Texas. Am Heart J 1953; 45: $741-748$.

28. Kinjo K, Sato H, Sato H, Shiotani I, Kurotobi T, Ohnishi Y, et al. Variation during the week in the incidence of acute myocardial infarction: Increased risk for Japanese women on Saturdays. Heart 2003; 89: $398-403$.

29. Nakayama N, Kimura K, Endo T, Fukui K, Himeno H, Iwasawa Y, et al. Current status of emergency care for ST-elevation myocardial infarction in an urban setting in Japan. Circ J 2009; 73: 484 489.

30. Rich MW. Epidemiology, clinical features, and prognosis of acute myocardial infarction in the elderly. Am J Geriatr Cardiol 2006; 15: 7-11; quiz 12 .

31. Gregoratos G. Clinical manifestations of acute myocardial infarction in older patients. Am J Geriatr Cardiol 2001; 10: 345-347.

32. Vinik AI, Maser RE, Mitchell BD, Freeman R. Diabetic autonomic neuropathy. Diabetes Care 2003; 26: 1553-1579.

33. Kempler P, Tesfaye S, Chaturvedi N, Stevens LK, Webb DJ, Eaton $\mathrm{S}$, et al. Autonomic neuropathy is associated with increased cardiovascular risk factors: The EURODIAB IDDM Complications Study. Diabet Med 2002; 19: 900-909.

34. Ambepityia G, Kopelman PG, Ingram D, Swash M, Mills PG, Timmis AD. Exertional myocardial ischemia in diabetes: A quantitative analysis of anginal perceptual threshold and the influence of autonomic function. J Am Coll Cardiol 1990; 15: 72-77.

35. Brodie BR, Stuckey TD, Muncy DB, Hansen CJ, Wall TC, Pulsipher M, et al. Importance of time-to-reperfusion in patients with acute myocardial infarction with and without cardiogenic shock treated with primary percutaneous coronary intervention.
Am Heart J 2003; 145: 708-715.

36. De Luca G, Suryapranata H, Zijlstra F, van't Hof AWJ, Hoorntje JCA, Gosselink ATM, et al. Symptom-onset-to balloon time and mortality in patients with acute myocardial infarction treated by primary angioplasty. J Am Coll Cardiol 2003; 42: 991-997.

37. Antoniucci D, Valenti R, Migliorini A, Moschi G, Trapani M, Buonamici P, et al. Relation of time to treatment and mortality in patients with acute myocardial infarction undergoing primary coronary angioplasty. Am J Cardiol 2002; 89: $1248-1252$.

38. De Luca G, Suryapranata H, Ottervanger JP, Antman EM. Time delay to treatment and mortality in primary angioplasty for acute myocardial infarction: Every minute of delay counts. Circulation 2004; 109: 1223-1225.

39. Rathore SS, Curtis JP, Chen J, Wang Y, Nallamothu BK, Epstein $\mathrm{AJ}$, et al. Association of door-to-balloon time and mortality in patients admitted to hospital with ST elevation myocardial infarction: National cohort study. BMJ 2009; 338: b1807.

40. Jneid H, Fonarow GC, Cannon CP, Palacios IF, Kilic T, Moukarbel $\mathrm{GV}$, et al. Impact of time of presentation on the care and outcomes of acute myocardial infarction. Circulation 2008; 117: 2502-2509.

\section{Appendix}

The complete list of KAMIR Investigators follows: Myung Ho Jeong, MD; Young Jo Kim, MD; Chong Jin Kim, MD; Myeong Chan Cho, MD; Young Keun Ahn, MD; Jong Hyun Kim, MD; Shung Chull Chae, MD; Seung Ho Hur, MD; In Whan Seong, MD; Taek Jong Hong, MD; Dong Hoon Choi, MD; Jei Keon Chae, MD; Jae Young Rhew, MD; Doo Il Kim, MD; In Ho Chae, MD; Jung Han Yoon, MD; Bon Kwon Koo, MD; Byung Ok Kim, MD; Myoung Yong Lee, MD; Kee Sik Kim, MD; Jin Yong Hwang, MD; Seok Kyu Oh, MD; Nae Hee Lee, MD; Kyoung Tae Jeong, MD; Seung Jea Tahk, MD; Jang Ho Bae, MD; Seung Woon Rha, MD; Keum Soo Park, MD; Kyoo Rok Han, MD; Tae Hoon Ahn, MD; Moo Hyun Kim, MD; Ju Young Yang, MD; Chong Yun Rhim, MD; Hyeon Cheol Gwon, MD; Seong Wook Park, MD; Young Youp Koh, MD; Seung Jae Joo, MD; Soo Joong Kim, MD; Dong Kyu Jin, MD; Jin Man Cho, MD; Jeong Gwan Cho, MD; Wook Sung Chung, MD; Yang Soo Jang, MD; Ki Bae Seung, MD; Seung Jung Park, MD. 